\title{
Paeoniflorin exerts antitumor effects by inactivating $S$ phase kinase-associated protein 2 in glioma cells
}

\author{
JIA OUYANG ${ }^{1,4,5}$, HUI XU ${ }^{1}$, MING LI $^{1,2}$, XINGLIANG DAI $^{1}$, FENGQING FU $^{3-5}$, \\ XUEGUANG ZHANG ${ }^{3-5}$ and QING LAN ${ }^{1}$
}

\begin{abstract}
${ }^{1}$ Department of Neurosurgery, The Second Affiliated Hospital of Soochow University, Suzhou, Jiangsu 215004, P.R. China; ${ }^{2}$ Department of Neurology, University of Virginia, Charlottesville, VA 22908, USA; ${ }^{3}$ Clinical Immunology Institute, The First Affiliated Hospital of Soochow University; ${ }^{4}$ Jiangsu Key Laboratory of Clinical Immunology, Soochow University; ${ }^{5}$ Jiangsu Key Laboratory of Gastrointestinal Tumor Immunology, The First Affiliated Hospital of Soochow University, Suzhou, Jiangsu 215006, P.R. China
\end{abstract}

Received June 20, 2017; Accepted December 11, 2017

DOI: 10.3892/or.2017.6175

\begin{abstract}
Paeoniflorin (PF), a natural compound isolated from Paeoniae radix, has been shown to exert antitumor effects in various types of human cancers including glioma. However, the mechanism of action is not well understood. S-phase kinase-associated protein (Skp)2 functions as an oncogene in many cancers. In the present study, we investigated whether Skp2 mediates the anti-glioma activity of PF. We found that PF inhibited glioma cell proliferation, migration and invasion, and induced G2/M arrest and apoptosis. Skp2 expression was downregulated in glioma cells treated with PF. PF-induced antitumor effects in glioma cells were abolished by Skp2 overexpression but were enhanced by RNA interference of Skp2. Moreover, PF treatment inhibited U87 cell-derived tumor growth in a xenograft mouse model. These results demonstrate that PF exerts its antitumor effects in part by inhibiting Skp2 expression in glioma cells and could be a promising therapeutic agent for glioma therapy.
\end{abstract}

\section{Introduction}

Glioma is among the most common primary brain tumors in adults (1) and is treated by a combination of surgical resection, temozolomide chemotherapy and radiotherapy (2). However, the median survival is not more than 14.6 months $(2,3)$ and the 5 -year survival rate after diagnosis is only $0.05-4.7 \%$ (4). Two obstacles for chemotherapeutic agents in glioma treatment are penetration through the blood-brain barrier and the development of drug resistance $(5,6)$.

Paeoniflorin (PF) is the main component of Paeoniae radix, which is widely used in traditional Chinese medi-

Correspondence to: Dr Qing Lan, Department of Neurosurgery, The Second Affiliated Hospital of Soochow University, Suzhou, Jiangsu 215004, P.R. China

E-mail: szlq006@163.com

Key words: paeoniflorin, Skp2, glioma cine (7-12). PF has been shown to repair injury (9), provide neuroprotection $(10)$, and exert anti-inflammatory $(11,12)$ and immunomodulatory $(13,14)$ effects. In addition, in vitro and in vivo studies have reported that $\mathrm{PF}$ inhibits tumor growth, invasion and metastasis (15-17). PF suppresses glioma cell proliferation by upregulating microRNA-16 and inhibiting matrix metalloproteinase (MMP)9 (18) and suppresses glioma growth and proliferation by promoting the degradation of signal transducer and activator of transcription (STAT)3 (19). However, the precise mechanism underlying the anticancer activity of PF in glioma cells is unclear.

$\mathrm{S}$-phase kinase-associated protein ( $\mathrm{Skp}) 2$ is a component of Skp2-Skp1/Cullin-1/F-box-protein (SCF) complex that functions as an E3 ligase in protein ubiquitination and degradation. Skp2 has been linked to tumor development (20-23), playing an oncogenic role by promoting the degradation of target proteins such as P21 (24), P27 (25) and P57 (26). Skp2 overexpression is correlated with poor prognosis in many types of human cancers, including hepatocellular carcinoma (27), breast cancer (28), melanoma (29) and glioma (30); moreover, Skp2 has been shown to regulate tumor cell proliferation, invasion, migration, senescence, glycolysis, and the Warburg effect $(31,32)$ as well as the selfrenewal capacity and functioning of cancer stem cells (33). Protein kinase B (AKT) modulates the phosphorylation of Skp2, leading to enhancement of cell proliferation and tumor progression (34), while suppression of Skp2 blocks tumor progression by promoting cellular senescence (32). Skp2-SCF E3 ligase may also promote the ubiquitination of AKT to induce tumorigenesis (31). These findings suggest that Skp2 is a potential therapeutic target for glioma treatment.

To evaluate this possibility, the present study investigated the biological effects of PF on glioma cell growth, apoptosis, migration and invasion and examined whether Skp2 mediates the antitumor effects of PF. We found that Skp2 plays an important role in glioma development. PF treatment inhibited Skp2 expression, leading to upregulation of P21 and downregulation of phosphorylated (p-)AKT, which in turn blocked tumor progression. These results indicate that PF is a potentially effective agent for the treatment of glioma. 


\section{Materials and methods}

Cell culture and reagents. The Second Affiliated Hospital of Soochow University Institutional Animal Care and Use Committee approved this study. U87 and U251 human glioma cell lines were obtained from the Chinese Academy of Medical Sciences (Beijing, China). Cells were cultured in Dulbecco's modified Eagle's medium (DMEM; HyClone Laboratories, Logan, UT, USA) supplemented with $10 \%$ fetal bovine serum (FBS) in a $5 \% \mathrm{CO}_{2}$ atmosphere at $37^{\circ} \mathrm{C}$. Primary antibodies against Skp2, P21, P27, p-AKT (S473), AKT, extracellular signal-regulated kinase (ERK), p-ERK, cyclin D, p-cyclin D, cleaved caspase-3 and -9, MMP2, MMP9 and $\beta$-actin were purchased from Cell Signaling Technology (Danvers, MA, USA). Secondary antibodies were from Liankebio (Hangzhou, China). Lipofectamine 3000 was from Invitrogen (Carlsbad, CA, USA). PF was from Tianjin Shilan Technology Co., Ltd., (Tianjin, China) and had a purity of $98 \%$. PF was diluted in DMEM at a stock concentration of $400 \mathrm{mM}$. Cell Counting Kit-8 (CCK-8) was obtained from Dojindo Laboratories (Kumamoto, Japan).

Cell viability assay. U87 and U251 cells $\left(5 \times 10^{3}\right)$ were seeded in a 96-well plate. Cells were treated with different concentrations of $\mathrm{PF}$ for 24 and $48 \mathrm{~h}$. At the end of the treatment period, $10 \mu 1$ of CCK-8 were added to each well. The plates were incubated at $37^{\circ} \mathrm{C}$ for $1 \mathrm{~h}$ and the optical density at $450 \mathrm{~nm}$ was then determined on a Varioskan microplate reader (Thermo Fisher Scientific, Waltham, MA, USA).

Cell apoptosis analysis. U87 and U251 cells were seeded in a 6 -well plate $\left(1-1.5 \times 10^{5} /\right.$ well) and treated with 15 and $20 \mathrm{mM}$ PF for $24 \mathrm{~h}$. The Annexin V-phycoerythrin (PE)/7aminoactinomycin D (7-AAD) assay was performed using a kit (BD Biosciences, Franklin Lakes, NJ, USA) according to the manufacturer's instructions. Briefly, cells were washed twice with cold phosphate-buffered saline (PBS), resuspended in $100 \mu \mathrm{l}$ binding buffer with 7-AAD and PE-conjugated anti-Annexin $\mathrm{V}$ antibody, and incubated for $15 \mathrm{~min}$ at room temperature in the dark before analysis by flow cytometry (Beckman Coulter Inc., Brea, CA, USA).

Cell cycle analysis. U87 and U251 cells were seeded in a 6 -well plate $\left(1-1.5 \times 10^{5} /\right.$ well) and treated with 15 or $20 \mathrm{mM}$ PF for $24 \mathrm{~h}$. The cells were harvested and fixed overnight at $4{ }^{\circ} \mathrm{C}$ with cold $70 \%$ ethanol. Cell pellets were resuspended in PBS at a concentration of $1 \times 10^{6}$ cells $/ \mathrm{ml}$ and then incubated with propidium iodide (PI)/RNAase staining buffer (BD Biosciences) at room temperature for $15 \mathrm{~min}$. DNA content was determined by flow cytometry.

Cell migration and invasion assay. To assess the effect of PF on cell migration, U87 and U251 cells were seeded in the upper chamber of a Boyden chamber (Corning Inc., Corning, NY, USA) with $200 \mu \mathrm{l}$ of DMEM supplemented with $1 \%$ FBS; $600 \mu$ l complete medium with $20 \%$ serum were added to the lower chamber along with indicated concentration of PF. After $24 \mathrm{~h}$, cells remaining in the upper chamber were removed using cotton swabs, and those in the lower chamber were fixed with methanol, stained with $0.1 \%$ crystal violet and photographed under a microscope. The invasion assay was similarly performed with a Matrigel-coated Transwell chamber (BD Biosciences). Cells in three randomly selected fields were counted.

Transfection. Cells were seeded in a 6-well plate at a density of $1.5-2 \times 10^{5} /$ well. When they reached $80 \%$ confluence, the cells were transfected with Skp2 cDNA or short interfering (si)RNA (sense, 5'-GGA GUG ACA AAG ACU UUG UTT-3' and antisense, 5'-ACA AAG UCU UUG UCA CUC CTT-3') or empty vector (Shanghai GenePharma, Co., Ltd., Shanghai, China) using Lipofectamine 3000 . At 48 h post-transfection, the cells were collected for analysis of cell proliferation, migration and invasion and for western blotting.

Quantitative real-time PCR analysis. Total RNA was extracted with TRIzol reagent (Invitrogen) and reverse transcribed into cDNA using the PrimeScript II First Strand cDNA Synthesis kit (Takara Bio, Shiga Japan). PCR was performed using the SYBR Premix Ex Taq kit (Takara Bio) and the following forward and reverse primers: Skp2, 5'-GAA GGG AGT CCC ATG AAA CA-3' and 5'-GCT GAA GAG CAA GGG AGTG3'; and glyceraldehyde 3-phosphate dehydrogenase, 5'-ACC CAG AAG ACT GTG GAT GG-3' and 5'-CAG TGA GCT TCC CGT TCA G-3'. The relative expression level of Skp2 was determined with the $2^{-\Delta \Delta \mathrm{Ct}}$ method.

Western blotting. Harvested cells or tumor tissue samples were lysed with radioimmunoprecipitation buffer (Beyotime Institute of Biotechnology, Nantong, China) supplemented with protease and phosphatase inhibitors (Beyotime Institute of Biotechnology). A bicinchoninic acid protein assay kit (Beyotime Institute of Biotechnology) was used to determine protein concentration, and 30-50 $\mu \mathrm{g}$ were separated by sodium dodecyl sulfate-polyacrylamide gel electrophoresis on a 10-12\% gel and transferred to a polyvinylidene difluoride membrane (Millipore, Billerica, MA, USA) that was blocked with $5 \%$ bovine serum albumin (BSA) for $1 \mathrm{~h}$ at room temperature and then probed overnight at $4^{\circ} \mathrm{C}$ with primary antibodies. The membrane was then washed with Tris-buffered saline/0.1\% Tween-20 and incubated with secondary antibodies. Protein expression was detected by enhanced chemiluminescence (Millipore) and the signal intensity of protein bands was analyzed with Image J software (National Institutes of Health, Bethesda, MD, USA) to determine the relative expression levels of target protein to $\beta$-actin. The experiment was performed three times.

Xenograft model. Female nude mice (6 weeks old) were purchased from Shanghai Slack Experimental Animal Center (Shanghai, China). U87 glioma cells $\left(2 \times 10^{6}\right)$ in $100 \mu$ l saline were injected into the backs of the mice. Tumor size was measured with calipers; when tumors reached $100 \mathrm{~mm}^{3}$, mice were randomly divided into experimental and control groups that were treated with PF and saline, respectively, by intragastric administration at a dose of $1 \mathrm{~g} / \mathrm{kg}$ in $0.2 \mathrm{ml}$ every day for 18 days. Tumor size and body weight were measured two or three times per week. Animal experiments and use of human cancer cell lines were approved by the Second Affiliated 
A

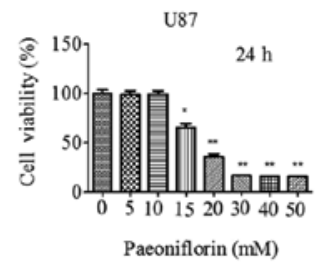

B
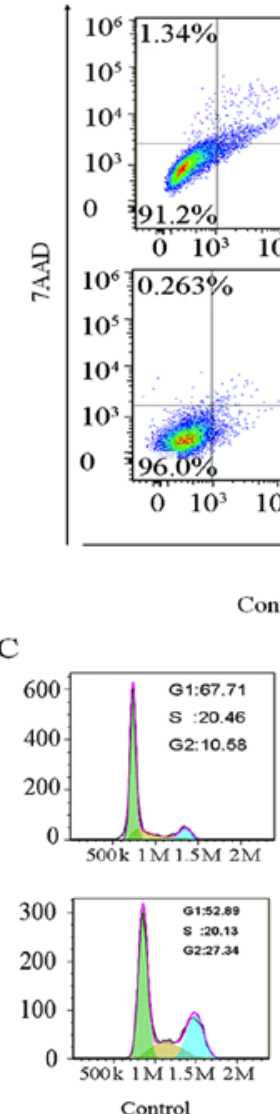

Control
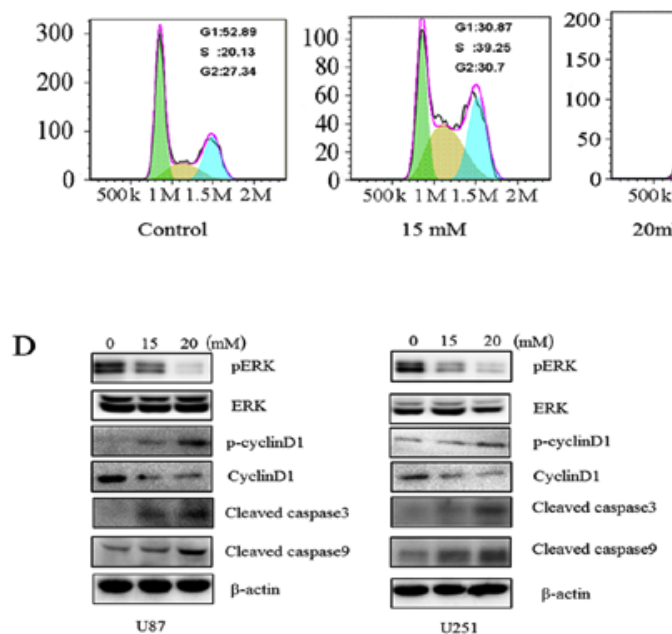
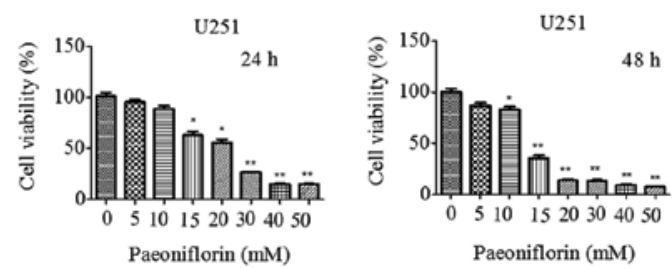

Paeoniflorin (mM)

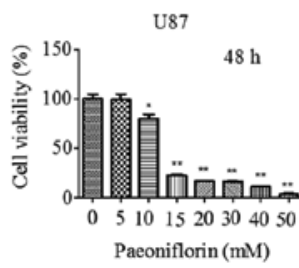

Paeoniflorin (mM)

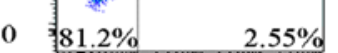

$\begin{array}{llll}0 & 10^{3} & 10^{4} & 10^{5} 10^{6}\end{array}$

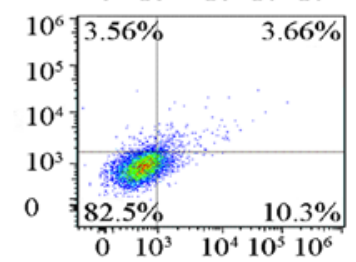

AnnexinV-PE
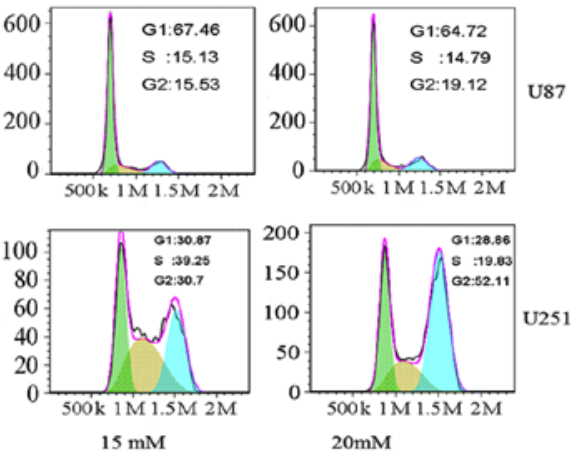

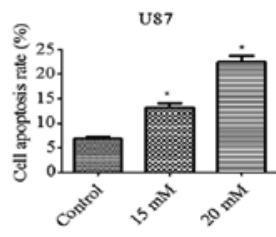

5251

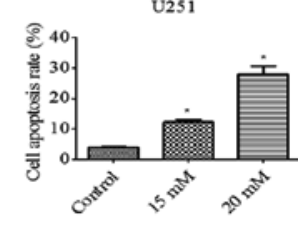

Figure 1. PF inhibits glioma cell proliferation and induces apoptosis. (A) Effect of PF on U87 and U251 glioma cell proliferation at 24 and 48 h. ${ }^{*} \mathrm{P}<0.05$, ${ }^{* *} \mathrm{P}<0.01$ vs. control. (B) Effect of PF on glioma cell apoptosis (left panel); and quantitative analysis (right panel). (C) Effect of PF on cell cycle progression. The percentage of cells in each cell cycle phase is shown. Data represent mean \pm SD of three independent experiments. (D) Effect of PF on ERK, p-ERK, cyclin D, p-cyclin D1 and cleaved caspase-3 and -9 expression.

Hospital of Soochow University Institutional Animal Care and Use Committee (Suzhou, China).

Statistical analysis. Statistical analyses were carried out using Prism v.5.0 software (GraphPad Inc., La Jolla, CA, USA). Differences between the groups were evaluated by one-way analysis of variance (three or more groups) or the independent t-test (two groups). Results are presented as mean \pm SD. $\mathrm{P}<0.05$ was considered statistically significant.

\section{Results}

PF inhibits glioma cell proliferation. In order to investigate the effect of PF on glioma cell growth, the viability of U87 and U251 cells treated with different concentrations of PF for 24 and $48 \mathrm{~h}$ was evaluated with the CCK-8. The cell growth was decreased in a time- and dose-dependent manner by the PF treatment in both U87 and U251 cells (Fig. 1A). After the treatment with PF for $24 \mathrm{~h}$, the half- 
A

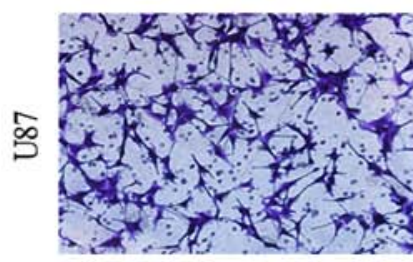

Control

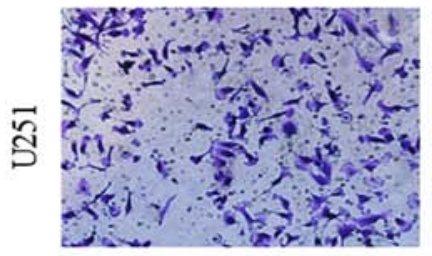

Control

B

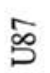

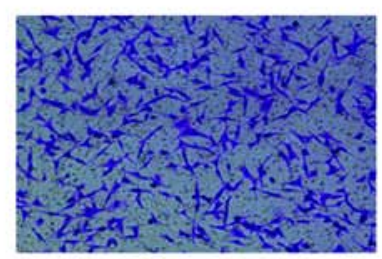

Control

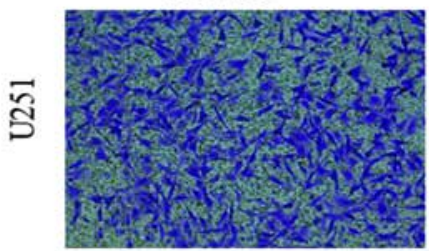

Control

C

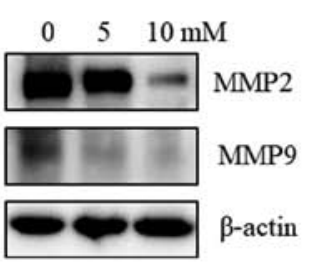

U87

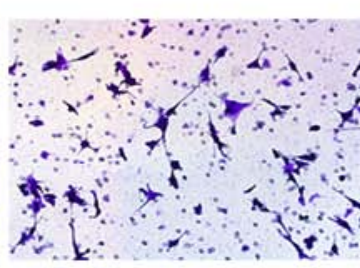

$5 \mathrm{mM}$

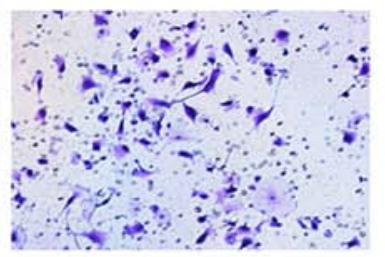

$5 \mathrm{mM}$

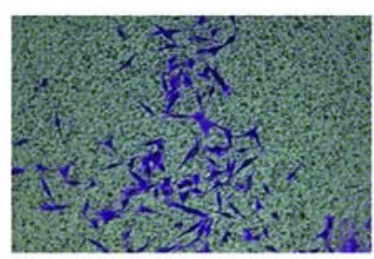

$5 \mathrm{mM}$

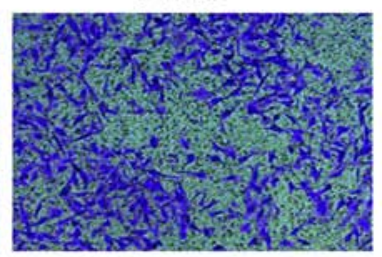

$5 \mathrm{mM}$

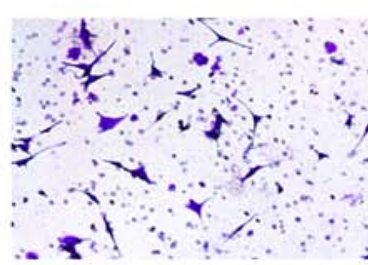

$10 \mathrm{mM}$

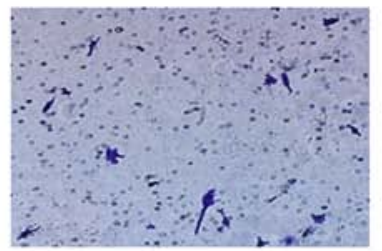

$10 \mathrm{mM}$

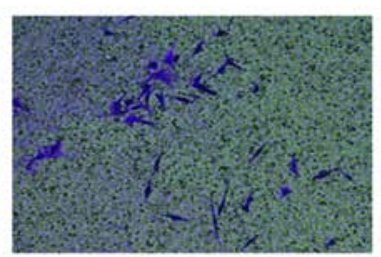

$10 \mathrm{mM}$

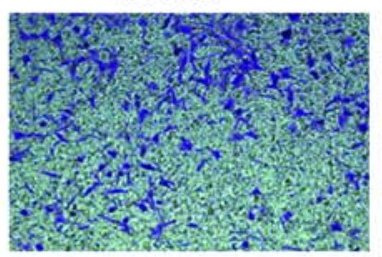

$10 \mathrm{mM}$

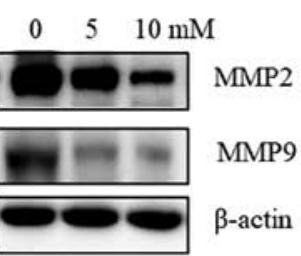

U251

D

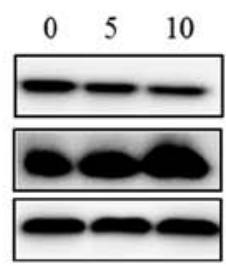

U87
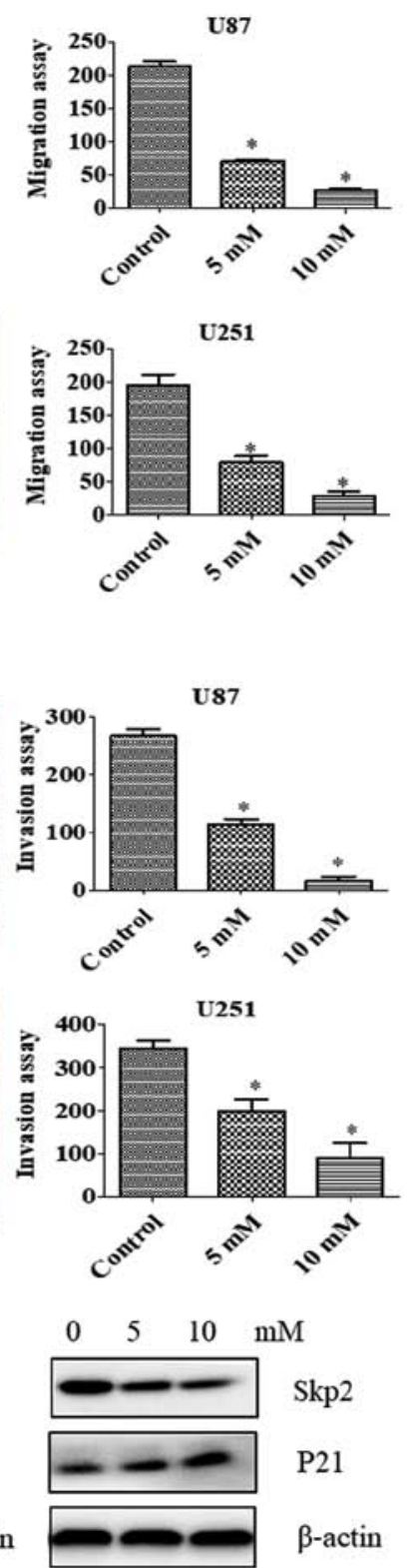

U251

Figure 2. PF suppresses cell motility. (A) Left panel, effect of PF on cell migration, as evaluated with the Transwell assay. Right panel, quantification of results shown in the left panel. (B) Left panel, effect of PF on cell invasion, as evaluated with the Transwell assay. Right panel, quantification of results shown in the left panel. Assays were performed in triplicate. ${ }^{*} \mathrm{P}<0.05$ vs. control. (C and D) Effect of PF on MMP2 and MMP9 (C) and Skp2 and P21 (D) protein levels, as determined by immunoblotting.

maximal inhibitory concentration of U87 and U251 cells was approximately $20 \mathrm{mM}$.

PF induces apoptosis and G2/M arrest in glioma cells. PF has been shown to inhibit cancer cell growth. We investigated whether apoptosis is involved in this process with the Annexin V/PE/7-AAD assay. U87 and U251 cells were treated with 15 or $20 \mathrm{mM}$ PF for $24 \mathrm{~h}$. The rate of apoptosis increased from 7.4 to $22.5 \%$ in U87 cells and from 3.7 to $23.7 \%$ in U251 cells upon PF treatment (Fig. 1B), indicating that PF induces glioma cell apoptosis as reported in previous studies (19).

The effect of PF on cell cycle progression was evaluated by PI staining and flow cytometry. Treatment with PF for $24 \mathrm{~h}$ caused cells to arrest in G2/M phase, with the fraction increasing from 23.48 to $34.07 \%$ in U87 cells and from 27.34 to $52.11 \%$ in U251 cells (Fig. 1C).

To clarify the effects of PF on glioma cell proliferation and apoptosis, ERK, p-cyclin D1, cyclin D, and cleaved caspase-3 and -9 expression was evaluated by western blotting. PF treatment decreased p-ERK and cyclin D and increased cleaved caspase-3 and -9 levels in a dose-dependent manner (Fig. 1D), confirming the results of CCK-8 and flow cytometric analyses.

PF inhibits cell migration and invasion. Since PF at concentrations of 5 and $10 \mathrm{mM}$ did not inhibit the proliferation of U87 and U251 cells (Fig. 1), we chose these concentrations to study the effects of PF on glioma cell motility with the migration and invasion assays. The number of migrating U87 and U251 
A

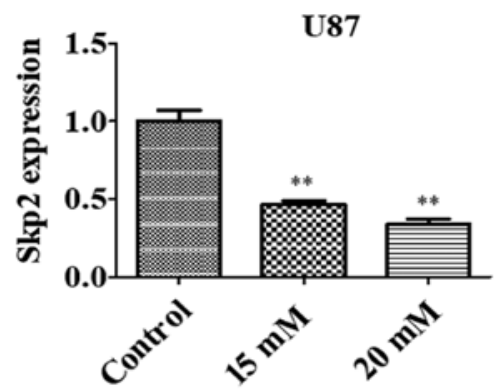

B

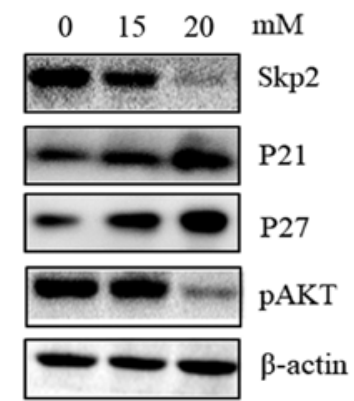

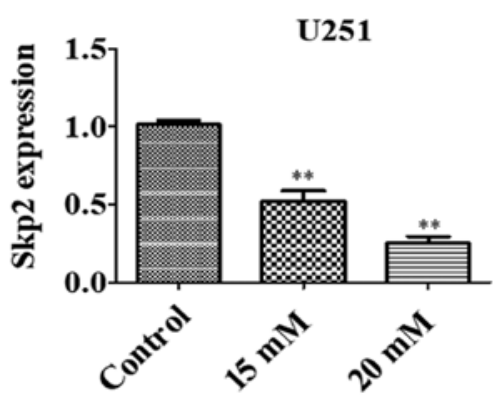

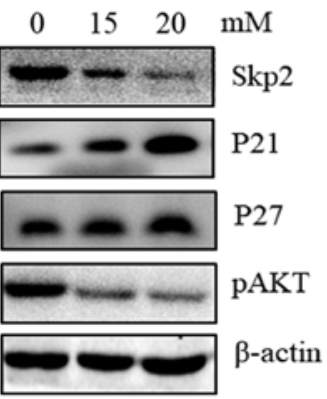

C

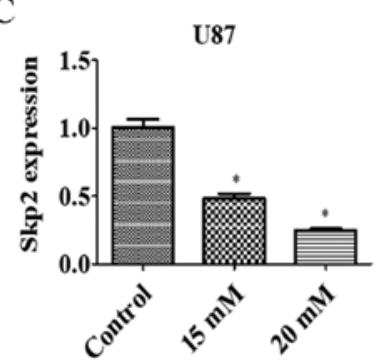

$\mathrm{U} 251$

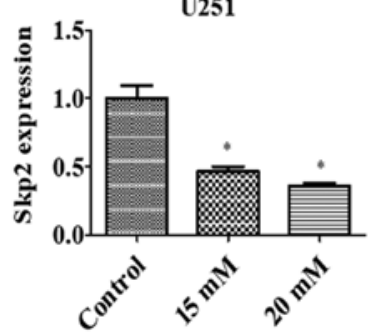

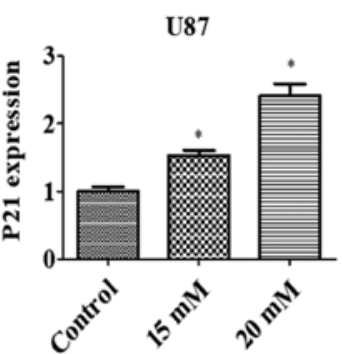
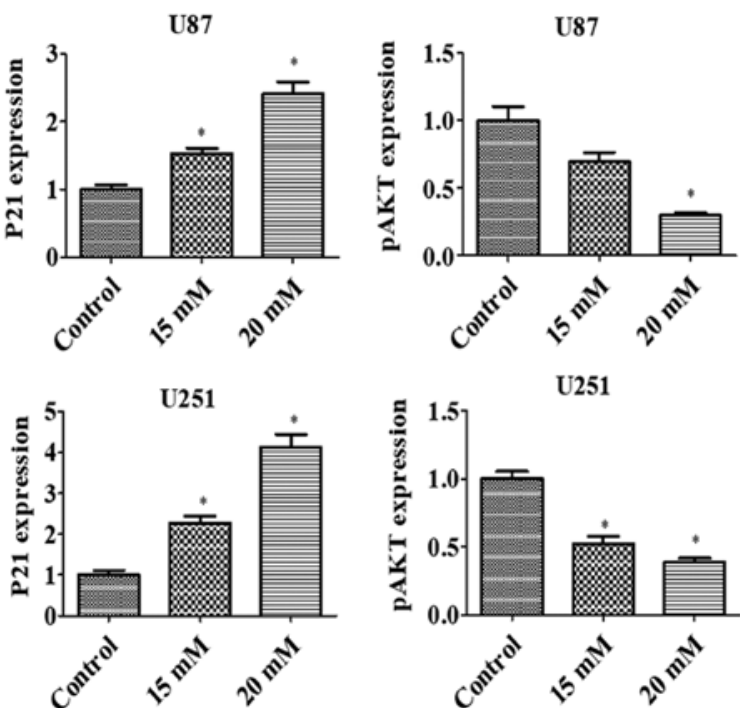

U251

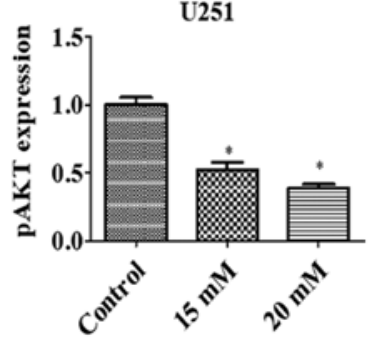

Figure 3. PF inhibits Skp2 expression at mRNA and protein levels. (A) U87 and U251 glioma cells were treated with indicated concentrations of PF and Skp2 gene expression was analyzed by quantitative real-time PCR. (B) Effect of PF on Skp2, P21, P27 and p-AKT protein levels, as determined by immunoblotting. (C) Quantitative analysis of results showed in (B). ${ }^{*} \mathrm{P}<0.05,{ }^{* *} \mathrm{P}<0.01$ vs. control.

cells (Fig. 2A) and the number of glioma cells infiltrating the membrane (Fig. 2B) were decreased by PF treatment relative to the control group. These results demonstrate that PF inhibits glioma cell invasion.

To confirm the effects of PF on tumor cell migration and invasion, MMP2 and MMP9 levels were evaluated by western blotting. We found that the expression of both proteins was downregulated by treatment with PF (Fig. 2C); a similar trend was observed for Skp2 in the presence of 5 and $10 \mathrm{mM} \mathrm{PF}$ (Fig. 2D). Thus, PF likely inhibits glioma cell migration and invasion via modulation of Skp2 signaling.

PF suppresses Skp2 expression. Skp2 is known to play an oncogenic role in tumorigenesis. To test whether Skp2 is involved in the anti-glioma effects of PF, we evaluated the $S k p 2$ expression in glioma cells treated with PF. Skp2
mRNA (Fig. 3A) and protein (Fig. 3B and C) levels were downregulated by PF treatment in U87 and U251 cells. We then examined whether Skp2 inactivation by PF influences the expression of downstream factors such as P21, P27 and p-AKT. PF inhibited the expression of p-AKT and induced that of P21 and P27 in both U87 and U251 cells (Fig. 3B and C). These results suggest that the antitumor activities of $\mathrm{PF}$ are mediated by Skp2 signaling.

Skp2 overexpression abolishes the antitumor effects of PF. To clarify the role of Skp2 in the antitumor activities of PF in glioma cells, U87 and U251 cells were transfected with $S k p 2$ cDNA and treated with PF for $24 \mathrm{~h}$, and cell growth and apoptosis were evaluated with the CCK-8 and Annexin V/PE/7-AAD assays, respectively. Cell proliferation was increased in cells overexpressing Skp2 (Fig. 4A); moreover, inhibition of cell 
A

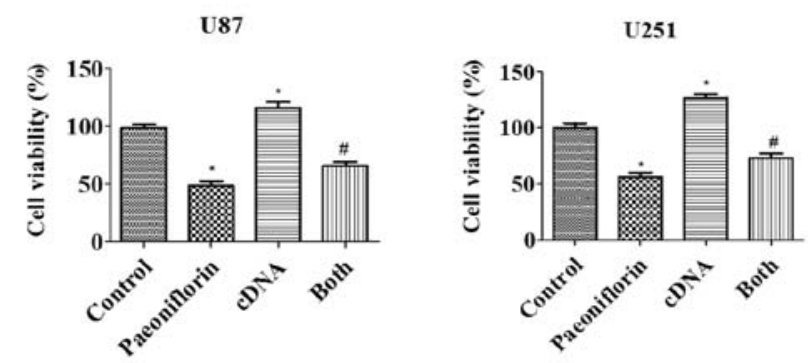

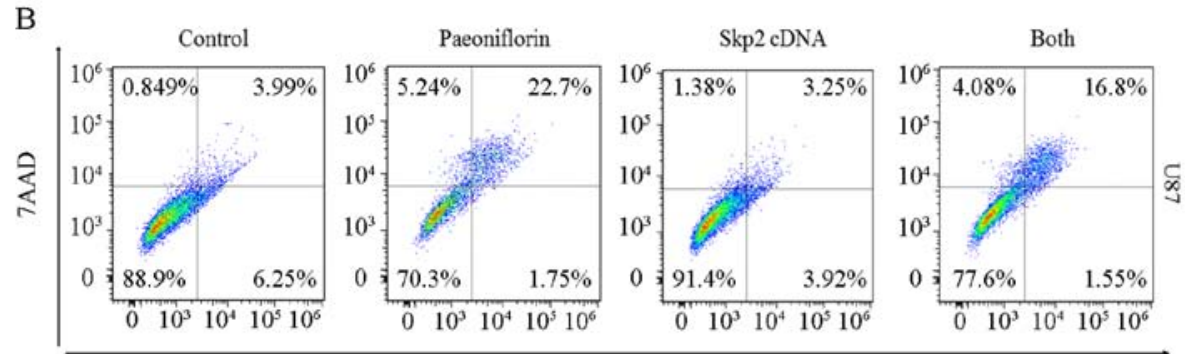

AnnexinV-PE

$\mathrm{C}$
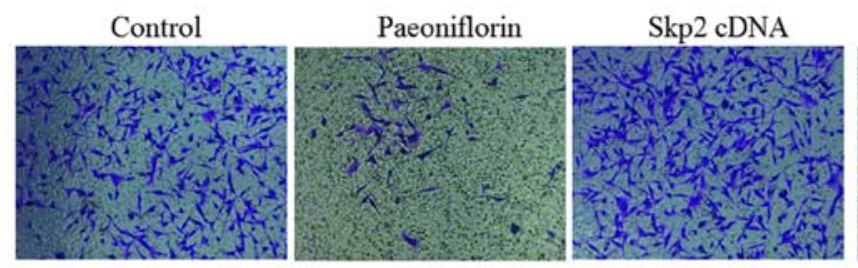

U87

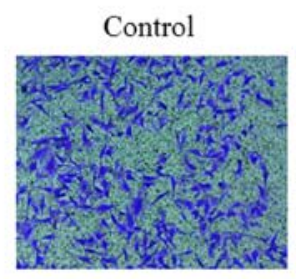

Paeoniflorin

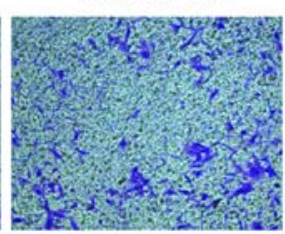

Skp2 cDNA

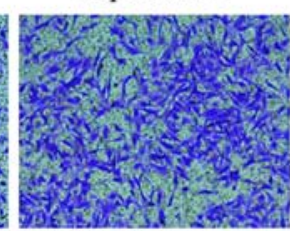

Both

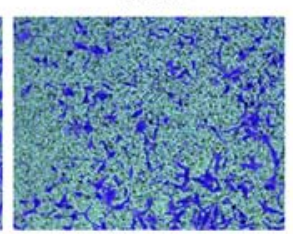

D

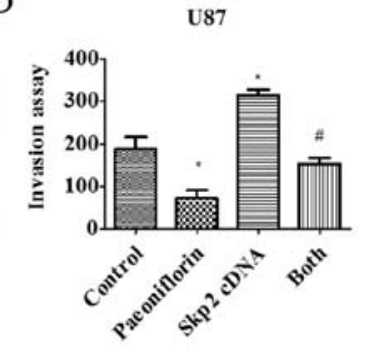

U251

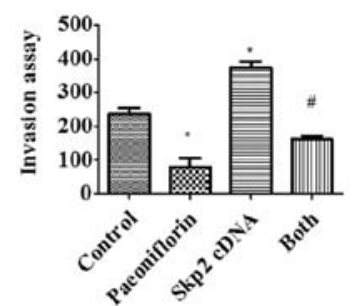

Figure 4. Effect of Skp2 overexpression on glioma cell growth, apoptosis and invasion. (A) Effect of PF in combination with $S k p 2$ cDNA transfection on glioma cell growth was evaluated with CCK-8. Control, pcDNA3.1. cDNA, Skp2 cDNA; Both, Skp2 cDNA+ PF. ${ }^{*} \mathrm{P}<0.05$ vs. control, ${ }^{\text {}} \mathrm{P}<0.05$ vs. either PF treatment or $S k p 2$ cDNA transfection alone. (B) Left panel, apoptosis of U87 glioma cells, as determined by flow cytometry following $S k p 2$ cDNA transfection and PF treatment. Right panel, quantitative analysis of results shown in the left panel. (C) Cell invasion was evaluated with the Transwell assay in cells overexpressing Skp2 and treated with PF. (D) Quantitative analysis of results shown in (C). "P<0.05 vs. control.

growth by PF treatment was abolished (Fig. 4A), suggesting that the antitumor effects of PF are exerted at least in part via negative regulation of Skp2. This was confirmed by the finding that overexpressing Skp2 decreased the number of apoptotic U87 glioma cells and abrogated the pro-apoptotic effect of PF (Fig. 4B).

To evaluate the role of $\mathrm{Skp} 2$ in glioma cell motility, U87 and U251 cells were transfected with Skp2 cDNA and treated with PF for $24 \mathrm{~h}$, and migration and invasion assays were performed. Skp2 overexpression increased the number of cells that infiltrated through the Transwell membrane and abrogated the inhibitory effect of PF on glioma cell invasion (Fig. 4C and D). Similar results were obtained for the migration assay (Fig. 5A). Skp2 overexpression increased Skp2 levels in glioma cells and reversed the inhibition of Skp2 and p-AKT and upregulation of P21 induced by PF (Fig. 5B and C). These results confirm that $\mathrm{PF}$ exerts antitumor effects via downregulation of Skp2 in glioma cells.

siRNA-mediated knockdown of Skp2 enhances the antitumor effects of PF. To examine the role of Skp2 in glioma in greater detail, RNA interference was carried out to suppress Skp2 expression in U87 and U251 cells. The cells were transfected with Skp2 siRNA and then treated with PF for $24 \mathrm{~h}$. The growth rate decreased (Fig. 6A) whereas apoptosis was increased in U87 cells upon $S k p 2$ knockdown (Fig. 6B), indicating that $S k p 2$ deficiency increases the sensitivity of the cells to PF. We next investigated whether Skp2 is involved in the regulation of U87 and U251 cell invasion. The inhibitory effects of PF on glioma cell invasion were enhanced in cells transfected with $S k p 2$ siRNA as compared to those treated with PF or $S k p 2$ siRNA only (Fig. 6C and D). We also observed that Skp2 expression 


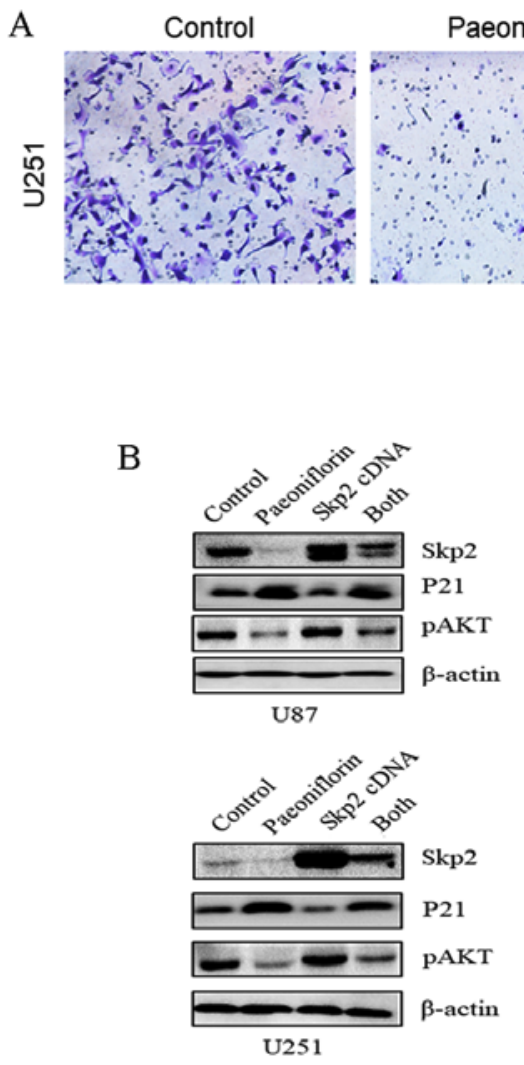

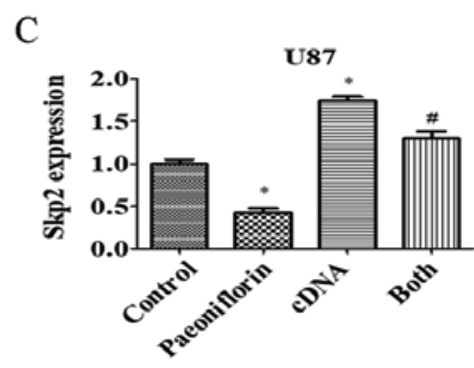

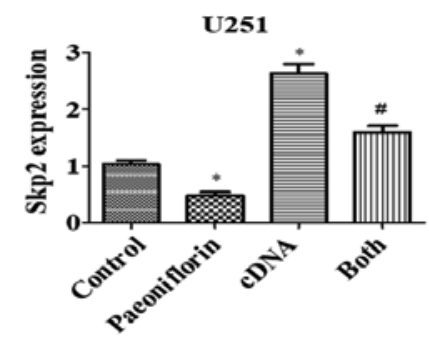

Both
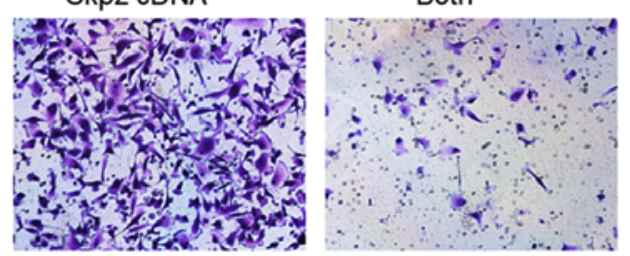

U251

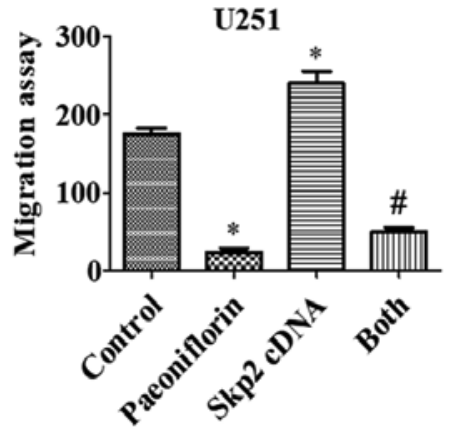

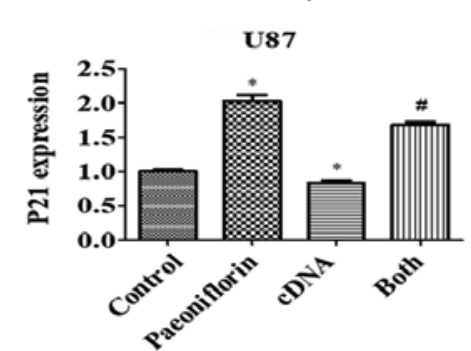

U251

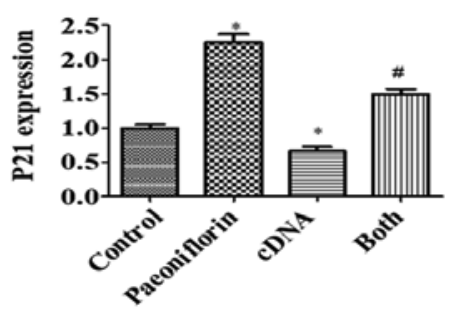

Figure 5. Skp2 overexpression reverses PF-induced inhibition of cell migration. (A) Left panel, effect of $S k p 2$ overexpression on PF-treated U251 cell migration. Right panel, quantitative analysis of results shown in the left panel. ${ }^{*} \mathrm{P}<0.05$ vs. control. " $\mathrm{P}<0.05$ vs. either PF treatment or $S k p 2$ cDNA transfection alone. (B) Protein levels of Skp2 and its targets P21 and p-AKT were measured by western blotting in glioma cells transfected with $S k p 2 \mathrm{cDNA}$ and treated with PF. (C) Quantitative analysis of results shown in (B).

was suppressed and P21 expression was increased to a greater degree in $S k p 2$-depleted cells treated with PF as compared to those subjected to either treatment alone (Fig. 6E and F).

PF suppresses the growth of glioma-derived tumors in a mouse xenograft model. We established a U87 cell mouse xenograft model to evaluate the in vivo effects of PF. Tumor volume was lower in PF-treated as compared to control mice $(\mathrm{P}<0.05$; Fig. 7), whereas no difference in body weight was observed between the two groups. Consistent with our in vitro observations, Skp2 and p-AKT levels were lower while that of P21 was higher in the tumor tissue of mice treated with PF relative to that of control animals.

\section{Discussion}

In the present study, we found that PF induced apoptosis and inhibited the proliferation, migration, and invasion of glioma cells. Moreover, we showed that PF exerts its antitumor effects in part by inhibiting Skp2 expression, since Skp2 overexpression restored whereas Skp2 knockdown enhanced these effects. Cell proliferation was enhanced in both U87 and U251 cell lines by overexpression of Skp2 (Fig. 4A), which also rescued the inhibition of cell growth resulting from PF treatment. On the other hand, $S k p 2$ knockdown enhanced cell growth inhibition by PF (Fig. 6A). Similar effects were observed in the cell invasion (Figs. 4C and D and 6C and D) and migration (Fig. 5A) assays.

There is increasing evidence to suggest that Skp2 plays a critical role in glioma development and progression $(5,30,35,36)$. Skp2 expression is diffuse or focal in most cases of glioblastoma (GBM), but is absent or expressed at a low level in well-differentiated astrocytomas (35). Survival in primary GBM patients was negatively correlated with Skp2 expression level in the tumor (30); a similar relationship has been observed in other tumor types such as nasopharyngeal carcinoma (37). Skp2 deficiency induces apoptosis and inhibits growth in T98G cells (36). Accordingly, we found that $S k p 2$ knockdown caused apoptosis and growth arrest in U87 glioma cells. Skp2 overexpression has been shown to promote cancer progression and metastasis (38); indeed, we observed that Skp2 overexpression stimulated the growth, migration, and invasion of glioma cells whereas downregulation of $S k p 2 \mathrm{had}$ the opposite effect, which is supported by a recent study (5).

Given its importance in tumor progression, inactivation of $S k p 2$ is a potential strategy for glioma treatment $(21,39)$. $S k p 2$ knockout mice are viable and fertile (40), suggesting that Skp2 inhibition is safe. Inhibition of the Skp2-SCF complex resulted in tumor regression in preclinical studies (32). Oncostatin M suppressed the proliferation of GBM cells via downregulation of the Skp2/Cyclin-dependent kinase regulatory subunit 1 E3 ligase complex while increasing the expression of P21 and 
A

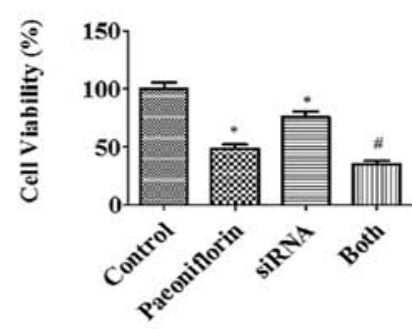

U251

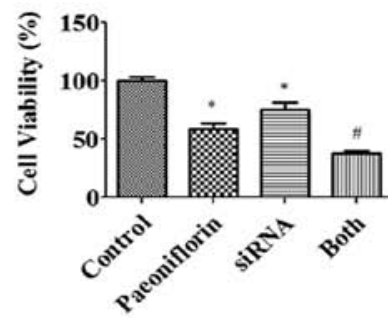

B

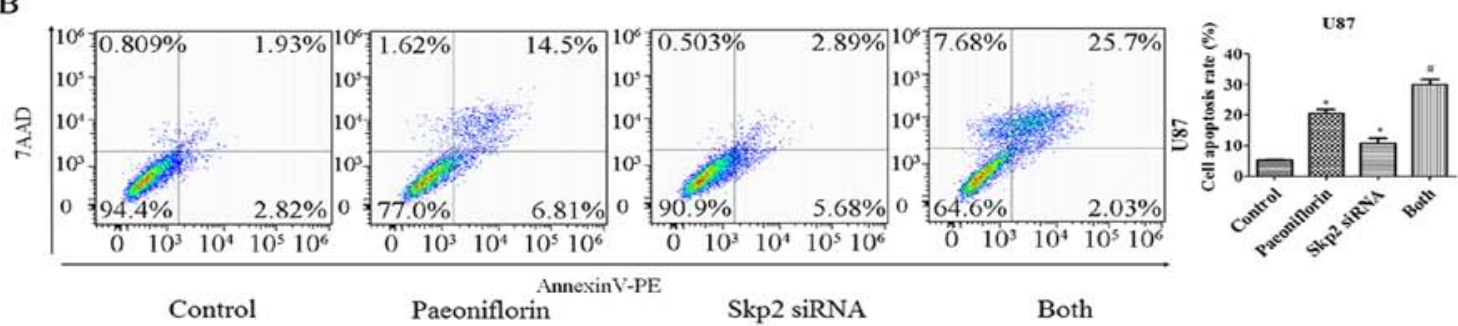

C

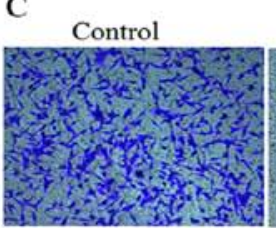

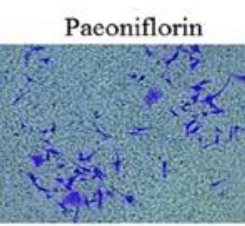

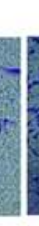

U87
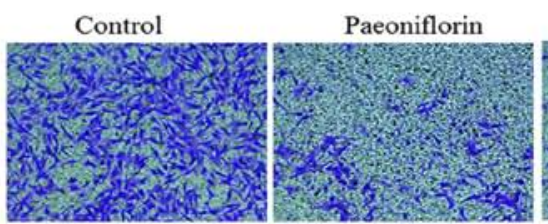

Skp2 siRNA

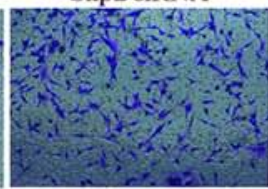

Skp2 $\operatorname{siRNA}$

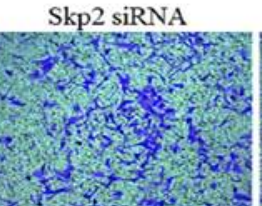

$\mathrm{U} 251$
D

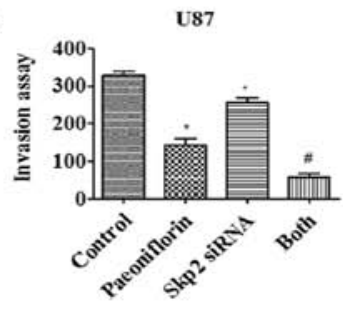

Both

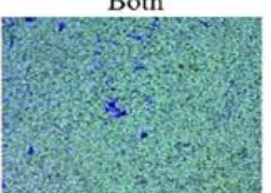

U251

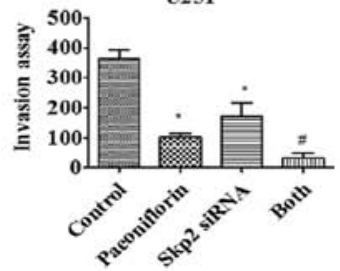

E
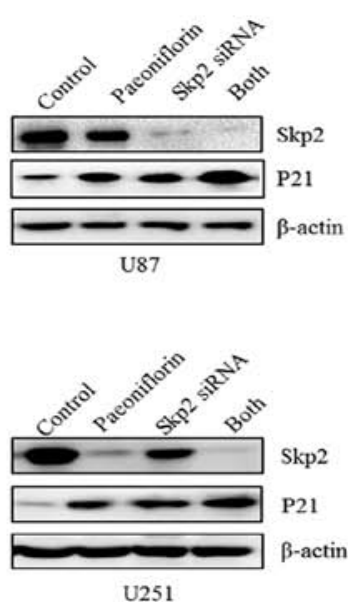

$\mathrm{F}$

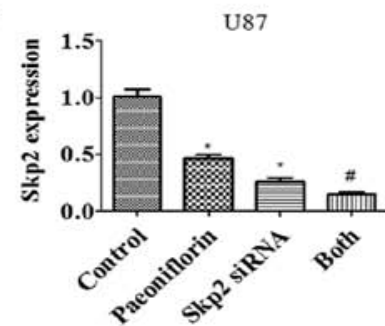

U251

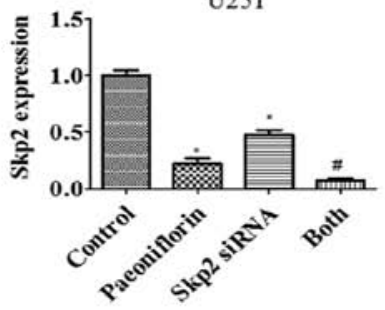

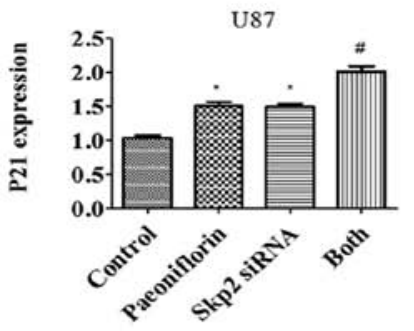

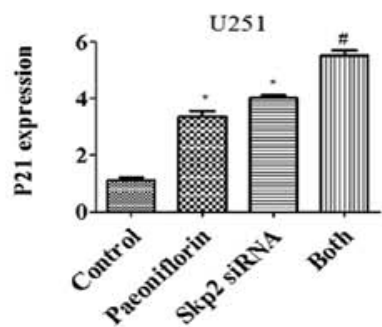

Figure 6. Effect of Skp2 depletion on glioma cell growth, apoptosis and invasion. (A) Growth of glioma cells treated with PF and transfected with $S k p 2$ siRNA was evaluated with CCK-8. Control, sicontrol; siRNA, Skp2 siRNA; Both, Skp2 siRNA + PF. "P $<0.05$ vs. control. "P<0.05 vs. either PF treatment or Skp2 siRNA transfection alone. (B) Left panel, apoptosis of U87 glioma cells analyzed by flow cytometry after $S k p 2$ depletion and PF treatment. Right panel, quantitative analysis of results shown in the left panel. (C) Cell invasion was evaluated with the Transwell assay after $S k p 2$ overexpression and PF treatment. (D) Quantitative analysis of results shown in (D). " $\mathrm{P}<0.05$ vs. control. (E) Protein levels of Skp2 and its target P21 as determined by western blotting in glioma cells transfected with $S k p 2$ siRNA and treated with PF. (F) Quantitative analysis of results shown in (E).

P27 (41). In this study, we found that PF treatment decreased Skp2 and increased P21 and P27 levels in U87 and U251 glioma cells. Additionally, the Skp2 inhibitor Compound \#25 not only blocked Skp2-mediated Akt ubiquitination, but 
A

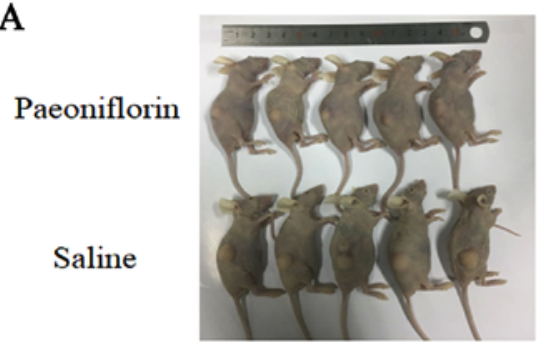

C

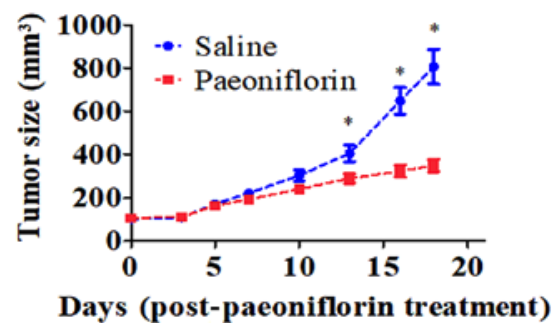

B

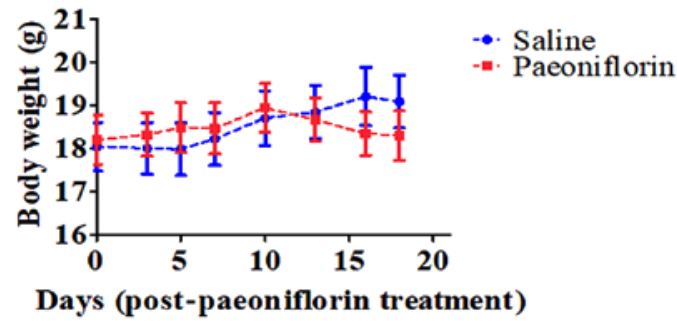

D SA SA SA PF PF PF

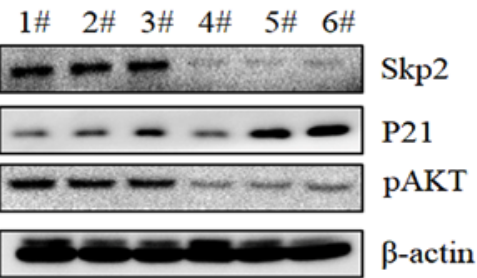

Figure 7. Antitumor effects of PF in a xenograft model. (A) Images of U87 cell-derived tumors from nude mice treated with PF or saline (n=5/group). (B) Body weight of mice monitored three times per week starting from the time of PF treatment. (C) Tumor size was measured with caliper three times per week starting from the time of PF treatment. (n=5/group). (D) Skp2, P21, and p-AKT expression in the tumors, as determined by western blotting. "P<0.05 vs. saline group.

also decreased the self-renewal capacity of cancer stem cell populations (33). Since cancer stem cells are responsible for GBM initiation and maintenance as well as chemoresistance and tumor relapse (42-44), we propose that Skp2 inhibitors have clinical value for treatment of glioma. Notably, lovastatin was found to suppress the growth of cancer cells by inducing the degradation of Skp2 (45), and a recent study reported that the matrine derivative YF-18 inhibited the proliferation and migration of lung cancer cells via Skp2 suppression (46). Given that these inhibitors have side-effects, natural agents may be a safer approach for glioma treatment. In fact, agents such as longikaurin A (47), caffeic acid phenethyl ester, curcumin $(5,48)$ and rottlerin $(49,50)$ have shown antitumor effects that are exerted via suppression of Skp2. This study demonstrates that PF has similar clinical potential.

To the best of our knowledge, this is the first report demonstrating that $\mathrm{PF}$ exerts an antitumor effect via downregulation of Skp2.PF inhibited the expression of Skp2 as well as its target genes P21 and p-AKT. AKT promotes Skp2 phosphorylation at serine 72 , resulting in its translocation to the cytoplasm and activation of its oncogenic function $(34,51)$. Notably, Skp2 was shown to regulate AKT ubiquitination in breast cancer and activate AKT in glioma cells (5), which is in agreement with our results. We previously reported that PF suppressed the expression of STAT3, which is known to regulate Skp2 expression in cancer cells (52-54). We speculate that PF inhibits Skp2 expression via negative regulation of STAT3, although further investigation is needed to evaluate this possibility.

Our results indicate that PF also has therapeutic effects in a glioma U87 cell xenograft mouse model. The fact that PF treatment had no effect on body weight suggests that it is a safe treatment for glioma patients. Consistent with our in vitro data, $\mathrm{Skp} 2$ and $\mathrm{p}$-AKT levels were reduced whereas that of p21 was increased in tumor tissue upon PF treatment. Unlike drugs for other cancers, those used to treat glioma must also pass through the blood-brain barrier. It was previously reported that PF crosses the blood-brain barrier in rats (55), underscoring its potential as an effective treatment for glioma.

\section{Acknowledgements}

The present study study was financially supported by the following grants: the Program of Medical Innovation Team and Leading Talent of Jiangsu Province, China (no. LJ201150); the Science and Technology Plan Projects of Jiangsu Province, China (no. BL2012048) and the National Natural Sciences Foundation of China (no. 81572480).

\section{References}

1. Ahmed R, Oborski MJ, Hwang M, Lieberman FS and Mountz JM: Malignant gliomas: Current perspectives in diagnosis, treatment, and early response assessment using advanced quantitative imaging methods. Cancer Manag Res 6: 149-170, 2014.

2. Stupp R, Mason WP, van den Bent MJ, Weller M, Fisher B, Taphoorn MJ, Belanger K, Brandes AA, Marosi C, Bogdahn U, et al; European Organisation for Research and Treatment of Cancer Brain Tumor and Radiotherapy Groups; National Cancer Institute of Canada Clinical Trials Group: Radiotherapy plus concomitant and adjuvant temozolomide for glioblastoma. $\mathrm{N}$ Engl J Med 352: 987-996, 2005.

3. Fine HA: New strategies in glioblastoma: Exploiting the new biology. Clin Cancer Res 21: 1984-1988, 2015.

4. Ostrom QT, Bauchet L, Davis FG, Deltour I, Fisher JL, Langer CE, Pekmezci M, Schwartzbaum JA, Turner MC, Walsh KM, et al: The epidemiology of glioma in adults: A 'state of the science' review. Neuro Oncol 16: 896-913, 2014.

5. Wang L, Ye X, Cai X, Su J, Ma R, Yin X, Zhou X, Li H and Wang Z: Curcumin suppresses cell growth and invasion and induces apoptosis by down-regulation of $\mathrm{Skp} 2$ pathway in glioma cells. Oncotarget 6: 18027-18037, 2015.

6. Walbert $\mathrm{T}$ and Chasteen K: Palliative and supportive care for glioma patients. Cancer Treat Res 163: 171-184, 2015.

7. Ma Z, Chu L, Liu H, Wang W, Li J, Yao W, Yi J and Gao Y: Beneficial effects of paeoniflorin on non-alcoholic fatty liver disease induced by high-fat diet in rats. Sci Rep 7: 44819, 2017.

8. Zhang H, Qi Y, Yuan Y, Cai L, Xu H, Zhang L, Su B and Nie H: Paeoniflorin ameliorates experimental autoimmune encephalomyelitis via inhibition of dendritic cell function and Th17 cell differentiation. Sci Rep 7: 41887, 2017. 
9. Chen YF, Wu KJ and Wood WG: Paeonia lactiflora extract attenuating cerebral ischemia and arterial intimal hyperplasia is mediated by paeoniflorin via modulation of VSMC migration and Ras/MEK/ERK signaling pathway. Evid Based Complement Alternat Med 2013: 482428, 2013.

10. Wang K, Zhu L, Zhu X, Zhang K, Huang B, Zhang J, Zhang Y, Zhu L, Zhou B and Zhou F: Protective effect of paeoniflorin on $\mathrm{A} \beta_{25-35}$-induced SH-SY5Y cell injury by preventing mitochondrial dysfunction. Cell Mol Neurobiol 34: 227-234, 2014.

11. Chen T, Fu LX, Zhang LW, Yin B, Zhou PM, Cao N and Lu YH: Paeoniflorin suppresses inflammatory response in imiquimodinduced psoriasis-like mice and peripheral blood mononuclear cells (PBMCs) from psoriasis patients. Can J Physiol Pharmacol 94: 888-894, 2016.

12. Li J, Huang S, Huang W, Wang W, Wen G, Gao L, Fu X, Wang M, Liang W, Kwan HY, et al: Paeoniflorin ameliorates interferon-alpha-induced neuroinflammation and depressive-like behaviors in mice. Oncotarget 8: 8264-8282, 2017.

13. Zhai T, Sun Y, Li H, Zhang J, Huo R, Li H, Shen B and Li N Unique immunomodulatory effect of paeoniflorin on type I and II macrophages activities. J Pharmacol Sci 130: 143-150, 2016.

14. He DY and Dai SM: Anti-inflammatory and immunomodulatory effects of paeonia lactiflora pall., a traditional Chinese herbal medicine. Front Pharmacol 2: 10, 2011.

15. Zhang Q, Yuan Y, Cui J, Xiao T and Jiang D: Paeoniflorin inhibits proliferation and invasion of breast cancer cells through suppressing Notch-1 signaling pathway. Biomed Pharmacother 78: 197-203, 2016.

16. Wang S and Liu W: Paeoniflorin inhibits proliferation and promotes apoptosis of multiple myeloma cells via its effects on microRNA-29b and matrix metalloproteinase-2. Mol Med Rep 14: 2143-2149, 2016.

17. Lu JT, He W, Song SS and Wei W: Paeoniflorin inhibited the tumor invasion and metastasis in human hepatocellular carcinoma cells. Bratisl Lek Listy 115: 427-433, 2014.

18. Li W, QiZ, WeiZ,Liu S, Wang P, Chen Y and Zhao Y: Paeoniflorin inhibits proliferation and induces apoptosis of human glioma cells via microRNA-16 upregulation and matrix metalloproteinase-9 downregulation. Mol Med Rep 12: 2735-2740, 2015.

19. Nie XH, Ou-yang J, Xing Y, Li DY, Dong XY, Liu RE and Xu RX Paeoniflorin inhibits human glioma cells via STAT3 degradation by the ubiquitin-proteasome pathway. Drug Des Devel Ther 9: 5611-5622, 2015

20. Wang Z, Inuzuka H, Zhong J, Liu P, Sarkar FH, Sun Y and Wei W: Identification of acetylation-dependent regulatory mechanisms that govern the oncogenic functions of Skp2. Oncotarget 3: 1294-1300, 2012.

21. Wang Z, Fukushima H, Inuzuka H, Wan L, Liu P, Gao D, Sarkar FH and Wei W: Skp2 is a promising therapeutic target in breast cancer. Front Oncol 1: 57, 2011.

22. Seki R, Ohshima K and Okamura T: Prognostic significance of Skp2 and p27 kip in diffuse large B cell lymphoma. Rinsho Ketsueki 51: 1741-1747, 2010 (In Japanese).

23. Frescas D and Pagano M: Deregulated proteolysis by the F-box proteins SKP2 and beta-TrCP: Tipping the scales of cancer. Nat Rev Cancer 8: 438-449, 2008.

24. Bornstein G, Bloom J, Sitry-Shevah D, Nakayama K, Pagano M and Hershko A: Role of the SCFSkp2 ubiquitin ligase in the degradation of p21Cip1 in S phase. J Biol Chem 278: 25752-25757, 2003.

25. Tsvetkov LM, Yeh KH, Lee SJ, Sun H and Zhang H: p27 ${ }^{\text {Kipl }}$ ubiquitination and degradation is regulated by the $\mathrm{SCF}^{\mathrm{Skp} 2}$ complex through phosphorylated Thr187 in p27. Curr Biol 9: 661-664, 1999.

26. Kamura T, Hara T, Kotoshiba S, Yada M, Ishida N, Imaki H, Hatakeyama S, Nakayama K and Nakayama KI: Degradation of p57Kip2 mediated by SCFSkp2-dependent ubiquitylation. Proc Natl Acad Sci USA 100: 10231-10236, 2003.

27. Shin E, Kim SH, Jeong HY, Jang JJ and Lee K: Nuclear expression of S-phase kinase-associated protein 2 predicts poor prognosis of hepatocellular carcinoma. APMIS 120: 349-357, 2012

28. Liu J, Wei XL, Huang WH, Chen CF, Bai JW and Zhang GJ: Cytoplasmic Skp2 expression is associated with p-Akt1 and predicts poor prognosis in human breast carcinomas. PLoS One 7: e52675, 2012

29. Chen G, Cheng Y, Zhang Z, Martinka M and Li G: Cytoplasmic Skp2 expression is increased in human melanoma and correlated with patient survival. PLoS One 6: e17578, 2011.
30. Saigusa K, Hashimoto N, Tsuda H, Yokoi S, Maruno M, Yoshimine T, Aoyagi M, Ohno K, Imoto I and Inazawa J: Overexpressed Skp2 within 5p amplification detected by arraybased comparative genomic hybridization is associated with poor prognosis of glioblastomas. Cancer Sci 96: 676-683, 2005.

31. Chan CH, Li CF, Yang WL, Gao Y, Lee SW, Feng Z, Huang HY, Tsai KK, Flores LG, Shao Y, et al: The Skp2-SCF E3 ligase regulates Akt ubiquitination, glycolysis, herceptin sensitivity, and tumorigenesis. Cell 149: 1098-1111, 2012.

32. Lin HK, Chen Z, Wang G, Nardella C, Lee SW, Chan $\mathrm{CH}$, Yang WL, Wang J, Egia A, Nakayama KI, et al: Skp2 targeting suppresses tumorigenesis by Arf-p53-independent cellular senescence. Nature 464: 374-379, 2010.

33. Chan CH, Morrow JK, Li CF, Gao Y, Jin G, Moten A, Stagg LJ, Ladbury JE, Cai Z, Xu D, et al: Pharmacological inactivation of Skp2 SCF ubiquitin ligase restricts cancer stem cell traits and cancer progression. Cell 154: 556-568, 2013.

34. Lin HK, Wang G, Chen Z, Teruya-Feldstein J, Liu Y, Chan $\mathrm{CH}$, Yang WL, Erdjument-Bromage H, Nakayama KI, Nimer S, et al: Phosphorylation-dependent regulation of cytosolic localization and oncogenic function of Skp2 by Akt/PKB. Nat Cell Biol 11: 420-432, 2009.

35. Schiffer D, Cavalla P, Fiano V, Ghimenti C and Piva R: Inverse relationship between p27/Kip.1 and the F-box protein Skp2 in human astrocytic gliomas by immunohistochemistry and Western blot. Neurosci Lett 328: 125-128, 2002.

36. Lee SH and McCormick F: Downregulation of Skp2 and p27/ Kip1 synergistically induces apoptosis in T98G glioblastoma cells. J Mol Med (Berl) 83: 296-307, 2005.

37. Wang J, Huang Y, Guan Z, Zhang JL, Su HK, Zhang W, Yue CF, Yan M, Guan S and Liu QQ: E3-ligase Skp2 predicts poor prognosis and maintains cancer stem cell pool in nasopharyngeal carcinoma. Oncotarget 5: 5591-5601, 2014.

38. Hung WC, Tseng WL, Shiea J and Chang HC: Skp2 overexpression increases the expression of MMP-2 and MMP-9 and invasion of lung cancer cells. Cancer Lett 288: 156-161, 2010.

39. Chan CH, Morrow JK, Zhang S and Lin HK: Skp2: A dream target in the coming age of cancer therapy. Cell Cycle 13: 679-680, 2014

40. Nakayama K, Nagahama H, Minamishima YA, Matsumoto M, Nakamichi I, Kitagawa K, Shirane M, Tsunematsu R, Tsukiyama T, Ishida N, et al: Targeted disruption of Skp2 results in accumulation of cyclin $\mathrm{E}$ and $\mathrm{p} 27^{\mathrm{Kipl}}$, polyploidy and centrosome overduplication. EMBO J 19: 2069-2081, 2000.

41. Halfter H, Friedrich M, Resch A, Kullmann M, Stögbauer F, Ringelstein EB and Hengst L: Oncostatin M induces growth arrest by inhibition of Skp2, Cks1, and cyclin A expression and induced p21 expression. Cancer Res 66: 6530-6539, 2006.

42. Singh SK, Hawkins C, Clarke ID, Squire JA, Bayani J, Hide T, Henkelman RM, Cusimano MD and Dirks PB: Identification of human brain tumour initiating cells. Nature 432: 396-401, 2004.

43. Galli R, Binda E, Orfanelli U, Cipelletti B, Gritti A, De Vitis S, Fiocco R, Foroni C, Dimeco F and Vescovi A: Isolation and characterization of tumorigenic, stem-like neural precursors from human glioblastoma. Cancer Res 64: 7011-7021, 2004.

44. Chen J, Li Y, Yu TS, McKay RM, Burns DK, Kernie SG and Parada LF: A restricted cell population propagates glioblastoma grow th after chemotherapy. Nature 488: 522-526, 2012.

45. Vosper J, Masuccio A, Kullmann M, Ploner C, Geley S and Hengst L: Statin-induced depletion of geranylgeranyl pyrophosphate inhibits cell proliferation by a novel pathway of Skp2 degradation. Oncotarget 6: 2889-2902, 2015.

46. Wu L, Wang G, Wei J, Huang N, Zhang S, Yang F, Li M, Zhou G and Wang L: Matrine derivative YF-18 inhibits lung cancer cell proliferation and migration through down-regulating Skp2. Oncotarget 8: 11729-11738, 2017.

47. Liao YJ, Bai HY, Li ZH, Zou J, Chen JW, Zheng F, Zhang JX, Mai SJ, Zeng MS, Sun HD, et al: Longikaurin A, a natural entkaurane, induces G2/M phase arrest via downregulation of Skp2 and apoptosis induction through ROS/JNK/c-Jun pathway in hepatocellular carcinoma cells. Cell Death Dis 5: e1137, 2014.

48. Su J, Zhou X, Wang L, Yin X and Wang Z: Curcumin inhibits cell growth and invasion and induces apoptosis through downregulation of Skp2 in pancreatic cancer cells. Am J Cancer Res 6: 1949-1962, 2016.

49. Yin X, Zhang Y, Su J, Hou Y, Wang L, Ye X, Zhao Z, Zhou X, Li Y and Wang Z: Rottlerin exerts its anti-tumor activity through inhibition of Skp2 in breast cancer cells. Oncotarget 7: 66512-66524, 2016. 
50. Su J, Wang L, Yin X, Zhao Z, Hou Y, Ye X, Zhou X and Wang Z: Rottlerin exhibits anti-cancer effect through inactivation of $S$ phase kinase-associated protein 2 in pancreatic cancer cells. Am J Cancer Res 6: 2178-2191, 2016.

51. Gao D, Inuzuka H, Tseng A, Chin RY, Toker A and Wei W: Phosphorylation by Akt1 promotes cytoplasmic localization of Skp2 and impairs APCCdh1-mediated Skp2 destruction. Nat Cell Biol 11: 397-408, 2009.

52. Huang H, Zhao W and Yang D: Stat 3 induces oncogenic Skp2 expression in human cervical carcinoma cells. Biochem Biophys Res Commun 418: 186-190, 2012.

53. Wei Z, Jiang X, Qiao H, Zhai B, Zhang L, Zhang Q, Wu Y, Jiang $H$ and Sun X: STAT3 interacts with Skp2/p27/p21 pathway to regulate the motility and invasion of gastric cancer cells. Cell Signal 25: 931-938, 2013.
54. Wang ST, Ho HJ, Lin JT, Shieh JJ and Wu CY: Simvastatininduced cell cycle arrest through inhibition of STAT3/SKP2 axis and activation of AMPK to promote p27 and p21 accumulation in hepatocellular carcinoma cells. Cell Death Dis 8: e2626, 2017.

55. He X, Xing D, Ding Y, Li Y, Xiang L, Wang W and Du L: Determination of paeoniflorin in rat hippocampus by high-performance liquid chromatography after intravenous administration of Paeoniae Radix extract. J Chromatogr B Analyt Technol Biomed Life Sci 802: 277-281, 2004.

(i) $(5)$ This work is licensed under a Creative Commons Attribution-NonCommercial-NoDerivatives 4.0 International (CC BY-NC-ND 4.0) License. 